\title{
An extremely rare complete bilateral duplication of inferior vena cava in a male cadaver: anatomy, embryology and clinical relevance
}

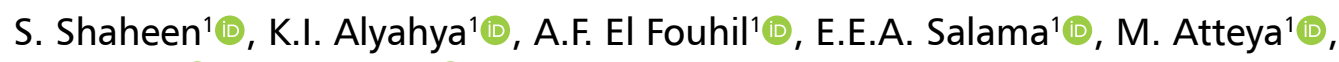 \\ F. Elshaer ${ }^{2}{ }^{1}$, H. Darwish ${ }^{1}(\mathbb{D}$ \\ ${ }^{1}$ Clinical Anatomy Lab., Department of Anatomy, College of Medicine, King Saud University, Riyadh, Saudi Arabia \\ ${ }^{2}$ King Khalid University Hospital, King Fahad Cardiac Centre, King Saud University, Riyadh, Saudi Arabia
}

[Received: 19 September 2020; Accepted: 22 January 2021; Early publication date: 23 February 2021]

\begin{abstract}
The study presented an extremely rare case of real complete bilateral duplication of inferior vena cava (IVC) in a male cadaver which has never been reported before. Both IVC had approximately the same diameter. The right IVC drained into the right atrium; the left IVC continued as hemiazygos vein and drained into the superior vena cava. Three anastomotic venous channels, a cranial preaortic, a middle and a caudal retroaortic, joined both vessels. Multiple variations in the way of drainage of posterior intercostal veins, on both sides, were also present. The present report invalidates an old classification defining the two vessels when joined at the level of the renal veins as complete bilateral duplication of IVC. Although the presence of combination of venous variations is extremely rare, awareness of such variations is essential for clinical and surgical procedures to avoid misdiagnosis and surgical complications. (Folia Morphol 2022; 81, 1: 247-253)
\end{abstract}

Key words: double inferior vena cava, rare variant, cadaveric study, clinical relevance, embryology

\section{INTRODUCTION}

In human anatomy, inferior vena cava (IVC) is the largest single vein in the body which is responsible for the majority of venous return, as it drains the blood from the lower extremities and the abdominopelvic viscera. IVC is formed by the union of the common iliac veins anterior to the fifth lumbar vertebral body (L5) approximately $2.5 \mathrm{~cm}$ to the right of midline. It ascends on the right side of the body to the level of eighth thoracic vertebra (T8), and passes through the diaphragm to drain into the right atrium [30]. Because of the complexity of its developmental stages, IVC may be presented with numerous anatomical forms and variations $[3,21]$. Congenital anomalies of IVC were first described in 1793 [1]. They are nowadays increasingly recognised in asymptomatic patients due to the more frequent use of non-invasive imaging techniques [15, 21]. Duplication of IVC is a relatively uncommon condition with a reported incidence of $0.2-3 \%[4,5,9,15,18,20]$.

Herein we present a case of an extremely rare variant of a duplicated IVC associated with other vessel anomalies in a male cadaver. In addition to the anatomical description, the development of veins with special reference to that of IVC as well as the previous reports for duplication of IVC are reviewed. An explanation of the underlying embryological changes is proposed. The clinical relevance of IVC variants is also discussed. 


\section{CASE REPORT}

During a routine anatomy dissection for undergraduate medical students, in the Department of Anatomy, College of Medicine, King Saud University, Riyadh, Saudi Arabia, an abnormal left large vein was found to the left of the abdominal aorta in the posterior abdominal wall of an adult male cadaver. The anatomical variant was outlined from its beginning distally and traced to its termination proximally. The venous channels in relation to such variant were checked for associated anomalies. The two common iliac veins were joined by a large anastomotic venous channel of approximately $1.5 \mathrm{~cm}$ in width and $2 \mathrm{~cm}$ in length, at the level of L5. They continued upwards as two separate vessels (right and left IVC) of approximately $1.6 \mathrm{~cm}$ in width, each. At the level of L4, both IVC were interconnected by a transverse venous channel, of approximately one $\mathrm{cm}$ in width and $2 \mathrm{~cm}$ in length, posterior to the abdominal aorta. At the level of L3, both IVC were reconnected by another transverse anastomotic channel of approximately $1.2 \mathrm{~cm}$ in width and $1.2 \mathrm{~cm}$ in length, posterior to the abdominal aorta. At the level of the renal veins (L2), a third narrower and longer anastomotic channel, of about $0.5 \mathrm{~cm}$ in width and $5 \mathrm{~cm}$ in length, crossed anterior to the abdominal aorta and connected the right and left IVC. On the right side, one renal vein drained into the right IVC. On the left side, two renal veins, a superior and an inferior, drained into the left IVC. The right suprarenal vein and right testicular vein drained into the right IVC proximal and distal to right renal vein, respectively. The left suprarenal vein and left testicular vein drained into the left superior renal vein. The left IVC, preserving the same width $(1.6 \mathrm{~cm})$, continued in the thoracic cavity as the hemiazygos vein, anterior to the thoracic vertebrae. At the level of T4, the hemiazygos vein arched transversally from the left to the right, anterior to the bifurcation of the trachea to drain into the superior vena cava (SVC). A short accessory hemiazygos vein connected the arch of hemiazygos vein to the left brachiocephalic vein. The azygos vein, significantly smaller than the hemiazygos vein, arose from the right IVC, between the middle and cranial anastomotic venous channels distal to the right testicular vein, and ran upwards, from the right to the left side, to the thoracic cavity where it joined the hemiazygos vein, at the level of T6. The right IVC followed its normal course and drained into the right atrium of the heart. The posterior intercostal veins, on both sides, were checked for variations in

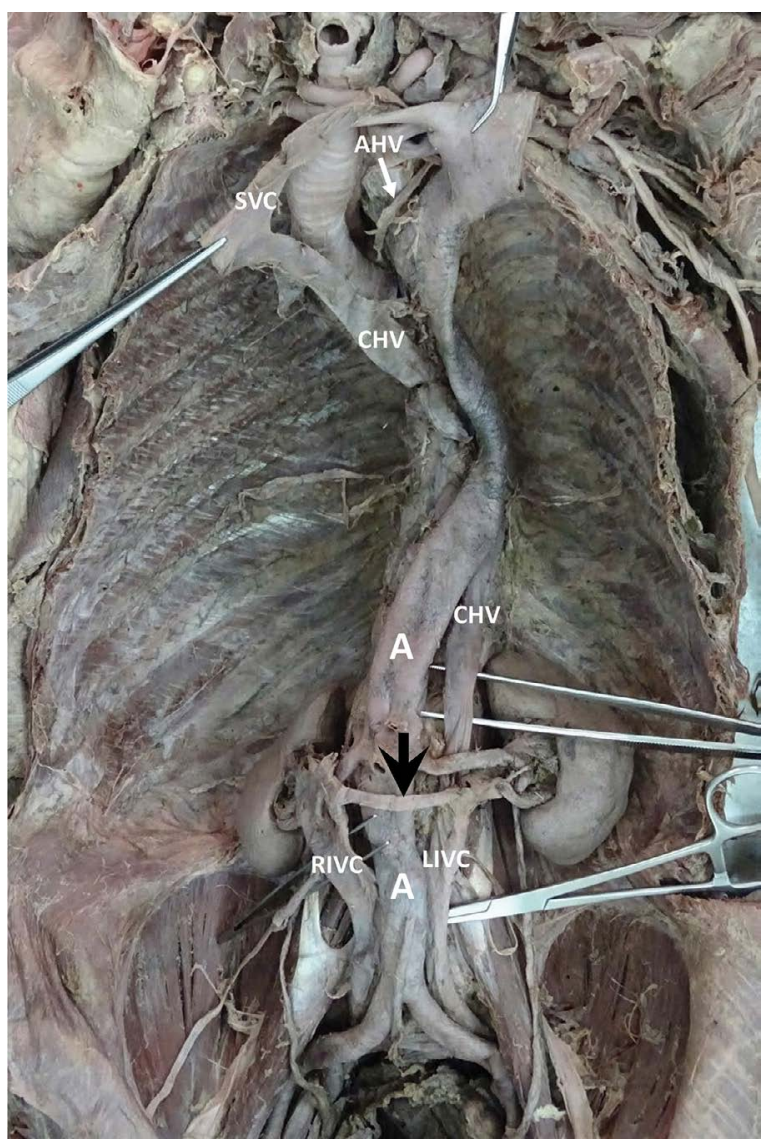

Figure 1. Gross appearance of the duplicated inferior vena cava; RIVC — right inferior vena cava; LIVC — left inferior vena cava; A — aorta; CHV — continuous hemiazygos vein; AHV — accessory hemiazygos vein; SVC — superior vena cava; arrow — preaortic anastomosis.

the way of their drainage. The right $11^{\text {th }}, 10^{\text {th }}, 9^{\text {th }}$ and $8^{\text {th }}$ posterior intercostal veins drained into the small azygos vein. The right $7^{\text {th }}$ and $6^{\text {th }}$ posterior intercostal veins drained into the hemiazygos vein. The right $5^{\text {th }}$ and $4^{\text {th }}$ posterior intercostal veins drained into the arch of the hemiazygos vein. The right second and third posterior intercostal veins united to form the right superior intercostal vein which also drained into the arch of the hemiazygos vein. The left posterior intercostal veins from $11^{\text {th }}$ to $7^{\text {th }}$ drained into the hemiazygos vein. The left posterior intercostal veins from $6^{\text {th }}$ to $4^{\text {th }}$ drained into the accessory hemiazygos vein (Figs. 1-5).

\section{DISCUSSION}

Initially, at the fourth week of intra-uterine life, the anterior cardinal veins (ACV) and posterior cardinal veins (PCV) drain cranial and caudal parts of the embryo, respectively. They join the common cardinal 


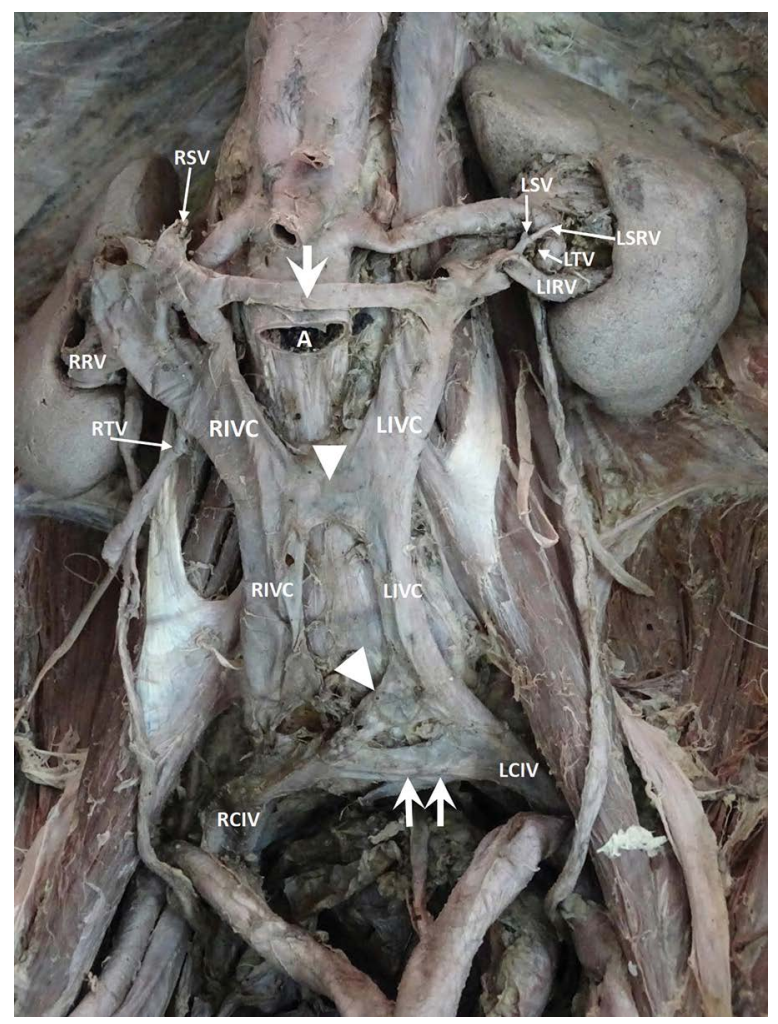

Figure 2. Gross appearance of the duplicated inferior vena cava after partial dissection of the abdominal aorta (A); RIVC — right inferior vena cava; LIVC — left inferior vena cava; RCIV — right common iliac vein; LCIV — left common iliac vein; RRV — right renal vein, RSV — right suprarenal vein; RTV — right testicular vein; LSRV — left superior renal vein, LIRV — left inferior renal vein; LSV — left suprarenal vein; LTV — left testicular vein; CHV — continuous hemiazygos vein; arrow - preaortic anastomosis; arrowhead — retroaortic anastomosis; Double arrows — anastomosis between common iliac veins.

veins (CCV) and form a symmetrical system. The right brachiocephalic vein is formed by the right ACV; the left brachiocephalic vein by the anastomosis between right and left ACV; and the superior vena cava by both right $A C V$ and right CCV. During the sixth and seventh weeks of intrauterine life, the subcardinal and supracardinal veins, gradually replace and supplement PCV. The only adult derivatives of PCV are the root of the azygos vein and the common iliac veins. The subcardinal veins form the stem of left renal vein, the suprarenal and gonadal veins; the supracardinal veins form the azygos and hemiazygos veins. The right renal vein and the remaining of the left renal vein are formed by an anastomosis between the subcardinal and supracardinal veins. Finally, the IVC is formed by the fusion of four different segments; a hepatic segment derived from the right vitelline vein, a prerenal segment derived from the right subcardinal vein,

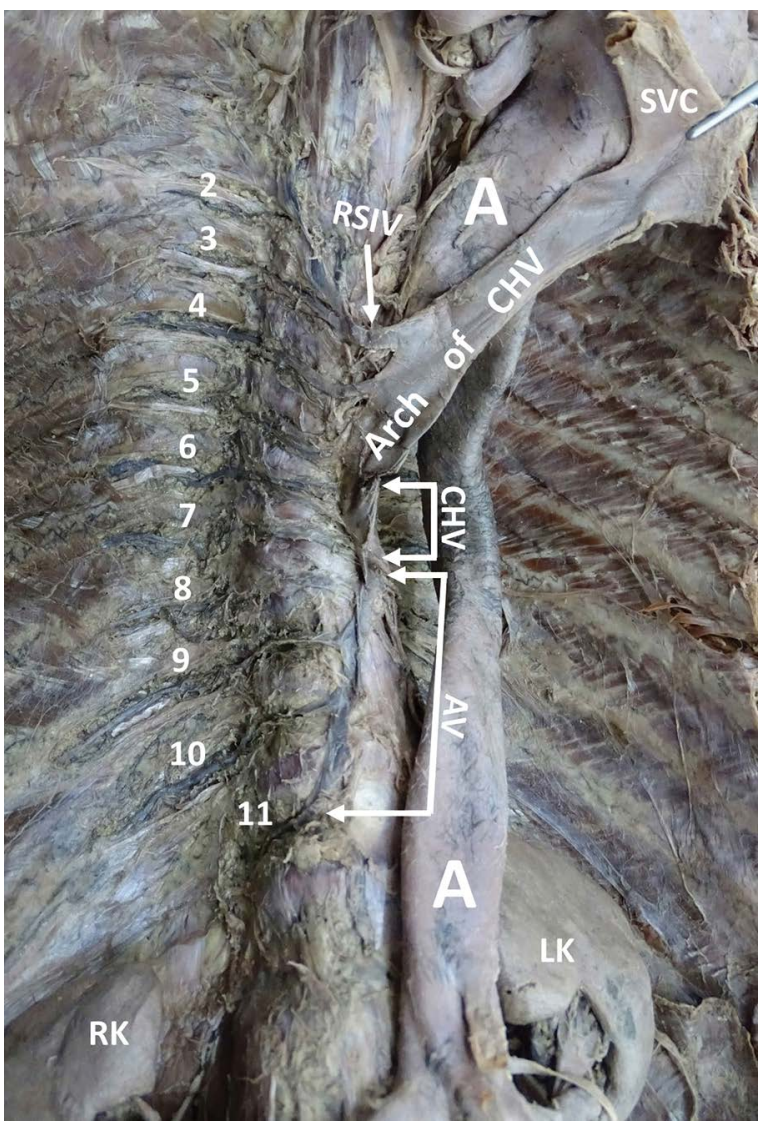

Figure 3. The abnormal way of drainage of the right posterior intercostal veins from 2 to 11. The arch of continuous hemiazygos vein (CHV) and the superior vena cava (SVC) are reflected to the left; A — aorta; AV — azygos vein; LK — left kidney; RK — right kidney; RSIV — right superior intercostal vein.

a renal segment derived from the subcardinal-supracardinal anastomosis, and a postrenal segment from the right supracardinal vein [17].

Duplication of IVC has been reported previously in several forms. The most common form is one in which two distinct IVC arise from each iliac vein [22]. Usually, the left IVC ends at the level of the renal veins, crossing anterior to the abdominal aorta to join the right IVC $[7,15,18]$. This variation was defined by Natsis et al. [18] as "complete bilateral duplication of IVC" because it comprised both renal and infrarenal segments of IVC. They further subdivided it into three types; major (type I) with two bilateral symmetrical trunks and a preaortic trunk of the same diameter $[24,28]$, minor (type II) with two bilateral symmetrical trunks but smaller in diameter in comparison to the preaortic trunk [27, 31], and asymmetrical (type III) with three trunks asymmetric in size $[8,13]$. The term 


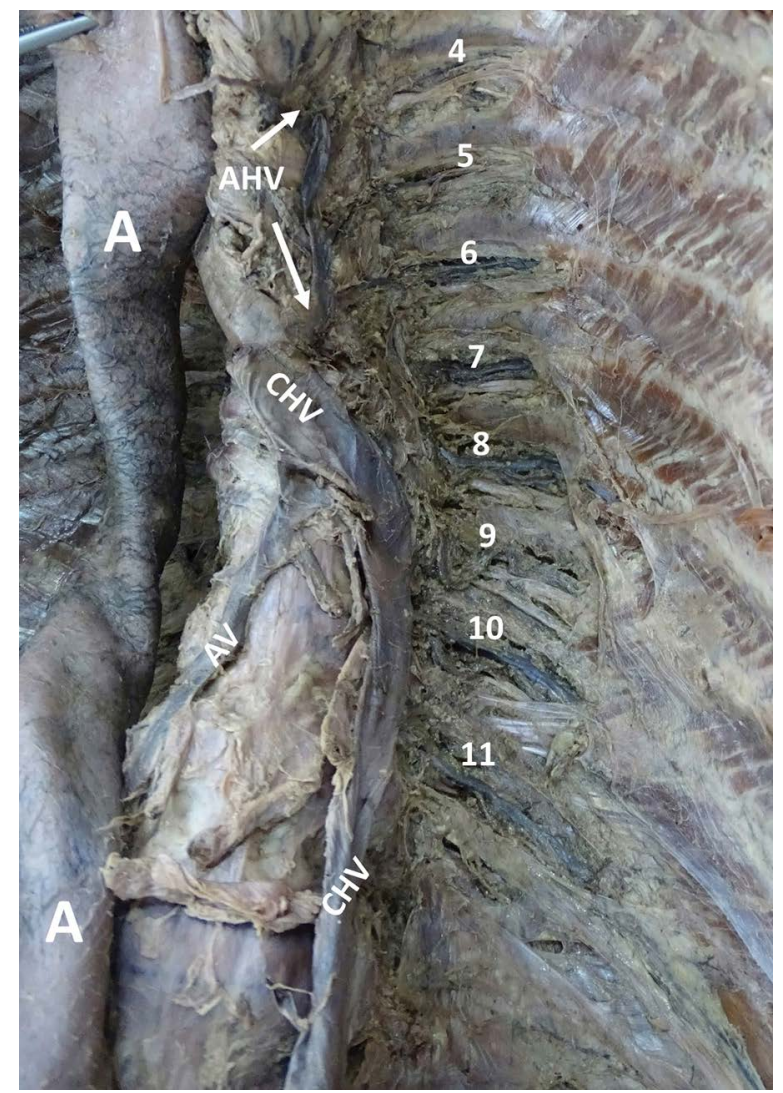

Figure 4. The abnormal way of drainage of the left posterior intercostal veins from 4 to $11 ; \mathrm{A}$ - aorta; AHV - accessory hemiazygos vein; CHV — continuous hemiazygos vein; AV — azygos vein.

"incomplete bilateral duplication" was referred to cases where the left IVC is smaller in diameter and empties into the left renal vein [10]. Other reported forms of duplication of IVC included double IVC with retroaortic right renal vein and hemiazygos continuation of the IVC $[2,4,9,21]$, and double IVC with retroaortic left renal vein and azygos continuation of the IVC $[6,21]$. In cases of hemiazygos continuation, right IVC joins right renal vein which passes behind the aorta to join the left IVC that ascends as hemiazygos vein and either joins the rudimentary azygos vein in the thorax or the coronary vein of the heart through a persistent left SVC or continues as accessory hemiazygos vein to drain into the left brachiocephalic vein. In cases of azygos continuation, left IVC joins left renal vein which runs behind the aorta to join the right IVC that continues as azygos vein and drains into SVC. Petik [21] also reported a case of both continuous azygos and hemiazygos veins joining together supradiaphragmatically and draining into SVC.

The present case also reported multiple variations in the way of drainage of the posterior intercostal

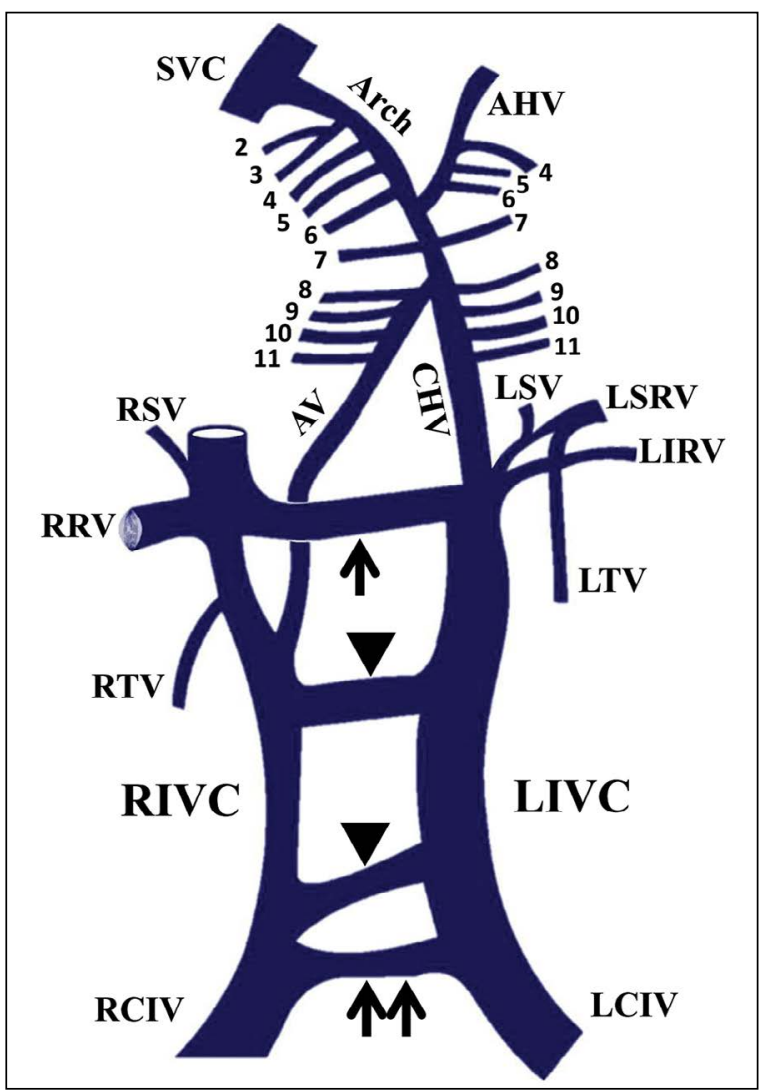

Figure 5. Schematic illustration of the duplicated inferior vena cava, abnormal azygos system and abnormal way of drainage of posterior intercostal veins; RIVC — right inferior vena cava; LIVC left inferior vena cava; RCIV — right common iliac vein; LCIV — left common iliac vein; RRV — right renal vein, RSV — right suprarenal vein; RTV — right testicular vein; LSRV — left superior renal vein, LIRV — left inferior renal vein; LSV — left suprarenal vein; LTV — left testicular vein; CHV — continuous hemiazygos vein; AHV — accessory hemiazygos vein; SVC — superior vena cava; AV — azygos vein; arrow - preaortic anastomosis; arrowhead retroaortic anastomosis; double arrows - anastomosis between common iliac veins.

veins, on both sides. Normally, the right posterior intercostal veins, from $11^{\text {th }}$ to $4^{\text {th }}$, drained into the azygos vein, while the right second and third posterior intercostal veins unite to form the right superior intercostal vein which drains into the arch of the azygos vein. On the left side, the posterior intercostal veins from $11^{\text {th }}$ to $9^{\text {th }}$ drained into the hemiazygos vein, while those from $8^{\text {th }}$ to $4^{\text {th }}$ drained into the accessory hemiazygos vein [30]. In the present study, the small azygos vein received only the right posterior intercostal veins, from $11^{\text {th }}$ to $8^{\text {th }}$; the continuous hemiazygos vein received the $7^{\text {th }}$ and $6^{\text {th }}$ right posterior intercostal veins; and the large arch of the continuous hemiazygos vein received the right $5^{\text {th }}$ and $4^{\text {th }}$ posterior intercostal veins, as well as, the right superior 
intercostal vein. On the left side, posterior intercostal veins from $11^{\text {th }}$ to $7^{\text {th }}$ drained into the continuous hemiazygos vein and those from $6^{\text {th }}$ to $4^{\text {th }}$ drained into the accessory hemiazygos vein. Variations in the azygos venous system were previously reported in few literatures. An underdeveloped hemiazygos vein was described associated with abnormal drainage of left posterior intercostal veins into the azygos vein $[19,23]$. However, the multiple variations in the way of drainage of posterior intercostal veins, on both sides, described in the present case have never been reported before. Furthermore, the present study was the first to report a case of duplicated IVC associated with multiple variations in the way of drainage of posterior intercostal veins.

The present case possesses a complex combination of venous variations that, to the best of the authors' knowledge, has never been reported before. We report a case of duplicated IVC where both vessels, of same diameter, continue into the thorax; the right IVC drains into the right atrium and the left IVC continues as hemiazygos vein, joins the right IVC through the azygos vein, joins the left brachiocephalic vein through the accessory hemiazygos vein and finally drains into SVC. The present report invalidates the classification of Natsis et al. [18] and presents a "real complete bilateral duplication of IVC". The present report also describes, for the first time, three large anastomotic channels between right and left IVC; a cranial preaortic, a middle and a caudal retroaortic. Furthermore, an explanation for the variations found in the case is suggested and illustrated in Figure 4. Variations are mostly due to persistence of a large portion of the left supracardinal vein, the supracardinal anastomoses and additional portions of the left PCV, left CCV and left ACV. The left IVC with its hemiazygos continuation is mainly formed by the left supracardinal vein with small contributions from subcardinal supracardinal anastomosis, left PCV, left CCV and left ACV, while its terminal arch is derived from an anastomosis between the two ACV. The rudimentary azygos vein and the two retroaortic anastomotic channels are derived from supracardinal anastomoses; the preaortic anastomotic channel from the subcardinal supracardinal anastomosis; the accessory hemiazygos from the left ACV. The left superior renal vein together with left suprarenal and left testicular veins are derived from the left subcardinal vein, while the left inferior renal vein from the subcardinal supracardinal anastomosis. The right
IVC together with its associated veins have a normal development (Fig. 6).

Because it is the principal vein draining all the intra-abdominal and pelvic organs, it is vital for surgeons, radiologists and clinicians to be aware of IVC normal anatomy as well as its variations. Most of cases of double IVC are asymptomatic and are discovered incidentally during abdominal imaging or during cadaveric dissections as in the present case. This is likely due to the compensation of adequate venous blood return to the heart created by the deep venous collateral systems [18]. Awareness of double IVC along with other vessels variations will help to eliminate the risk of haemorrhage, misdiagnosis or life-threatening complications during abdominal and thoracic surgeries and the risk of recurrent embolism during the placement of an IVC filter in vascular interventional procedures. In addition, awareness of such variations is necessary to prevent misinterpretation of aberrant vessels as paravertebral lymph nodes enlargement or mediastinal masses [6].

Inferior vena cava malformations were also reported to be a predisposing factor to deep vein thrombosis (DVT), especially in young patients. Accordingly, IVC anomalies should be alerted and excluded by clinicians if a young patient presented with an idiopathic DVT, especially when the intrathoracic hemiazygos or azygos systems are dilated in the diagnosed case [12]. Duplication of IVC has been reported to be associated with symptomatic venous thrombosis of lower extremities and with recurrent pulmonary thromboembolism [26].

Several double IVC case reports described associated abnormalities in the renal and gonadal vessels. Duplicated renal veins were reported to be more frequent on the right side as a result of persistence of anastomoses on that side and their regression on the left side [11]. In contrast to such reports, the present study reported duplication of the left renal vein resulting from an unusual persistence of the subcardinal supracardinal anastomosis on the left side. In the literature, anomalies on the left side included retroaortic and circumaortic left renal veins [18]. Anatomical variations in gonadal vessels were mainly in the form of duplications of testicular [31] or ovarian [25] veins, and they were more common on the left side [18]. Moreover, in patients with duplicated IVC, the left kidney is often lower in position than the right kidney due to the pull by the left IVC on the left renal vein $[13,16]$. These venous abnormalities have led 


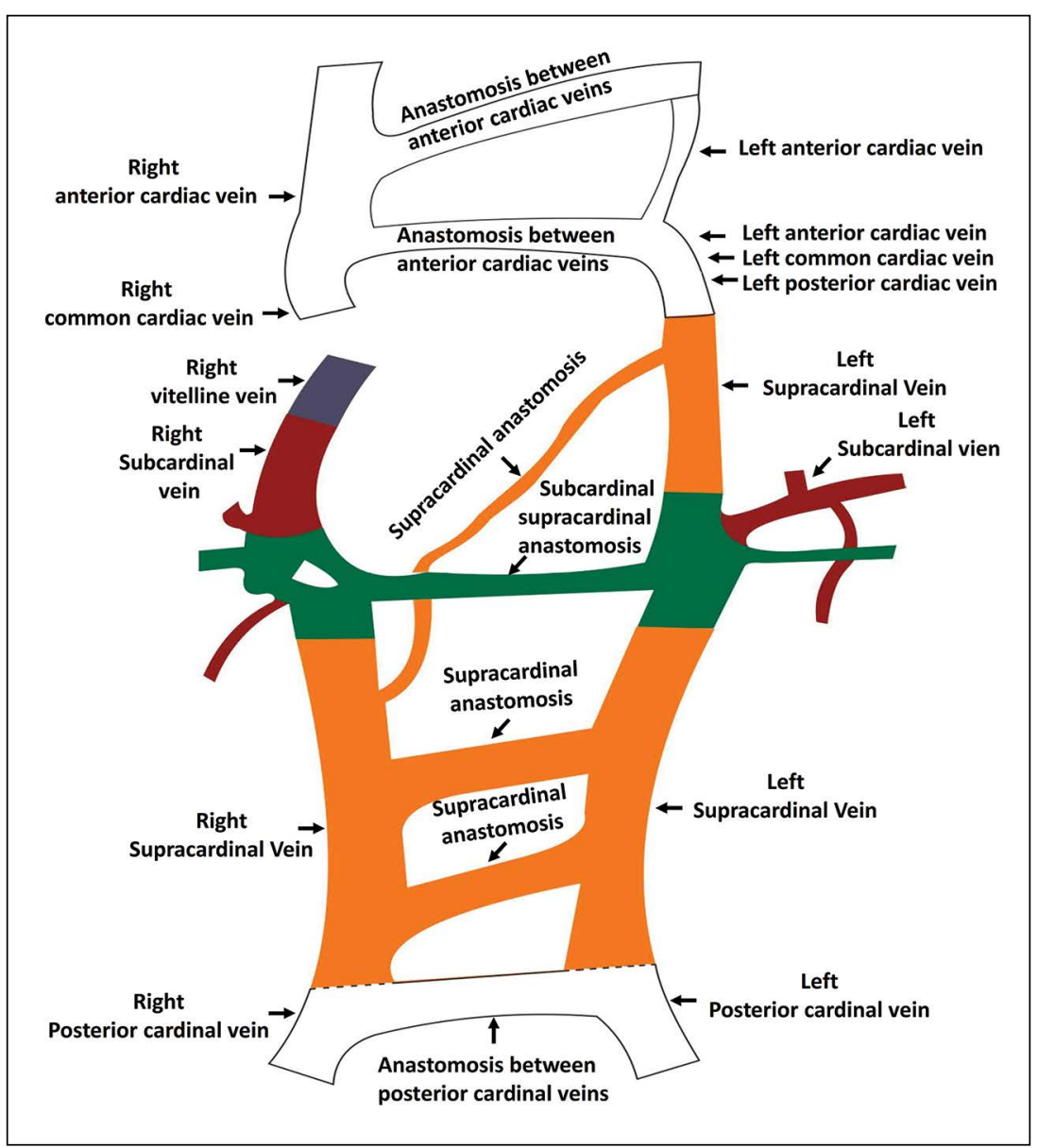

Figure 6. Schematic diagram suggesting the origins of the duplicated vena cava and the associated vessel anomalies; white - anterior, posterior and common cardinal veins; orange — supracardinal veins; red — subcardinal veins; green — subcardinal supracardinal anastomosis; blue — right vitelline vein.

to urogenital complications including obstruction of the ureter [29]. An atypical origin and course of the gonadal arteries might be associated with vascular and developmental variations of the kidneys [14]. Kidneys with bilateral multicystic changes were reported in cases of duplication of IVC [31]. The presence of the multicystic kidney might coincide with a high incidence of hydronephrosis and infections of the upper urinary tract and might result in deterioration of late renal function and secondary hypertension. Duplication of the IVC associated with vascular variations of the kidneys and gonads are important not only from the developmental point of view, but also have important clinical implications. These anomalies can manifest various clinical symptoms and can affect the approach to surgical procedures. The presence of duplication of the IVC poses hazards during abdominal aortic surgery. The double renal arteries, renal arterial origin of the testicular arteries and atypical drainage of the testicular veins increase the complexity of renal transplantation and lead to a higher percentage of transplant failures. Thus, familiarity with these anatomical anomalies is vital for vascular surgeons and urologists to reduce the risk of serious haemorrhage during surgical treatment and to avoid operative complications [31].

\section{CONCLUSIONS}

In conclusion, the present report presents an extremely rare complete duplication of IVC. Preoperative diagnosis of the IVC anomalies through accurate use of detailed imaging modalities would reduce the complication rate and would also help in planning a proper treatment as placement of preventive IVC filters. Finally, care should be taken during routine medical dissections and hopefully, the present case report will create the awareness that surely enlighten the academic fields. 


\section{Acknowledgements}

The authors extend their appreciation to the Deanship of Scientific Research-King Saud University for funding this work through research group no. (RG-1441- 517).

\section{Conflict of interest: None declared}

\section{REFERENCES}

1. Abernethy J. Account of two instances of uncommon formation, in the viscera of the human body. Philos Trans R Soc London. 1993; 83: 59-66, doi: 10.1098/ rstl.1793.0010.

2. Artico $M$, Lorenzini $D$, Mancini $P$, et al. Radiological evidence of anatomical variation of the inferior vena cava: report of two cases. Surg Radiol Anat. 2004; 26(2): 153-156, doi: 10.1007/s00276-003-0192-0, indexed in Pubmed: 14600789.

3. Banerjee A, Maharana S, Anil Kumar I. Duplication of the inferior vena cava - report of a rare congenital variation. IJAV. 2012; 5: 141-143.

4. Bass JE, Redwine MD, Kramer LA, et al. Spectrum of congenital anomalies of the inferior vena cava: cross-sectional imaging findings. Radiographics. 2000; 20(3): 639-652, doi: 10.1148/radiographics.20.3.g00ma09639, indexed in Pubmed: 10835118.

5. Chen $\mathrm{H}$, Emura $\mathrm{S}$, Nagasaki $\mathrm{S}$, et al. Double inferior vena cava with interiliac vein: a case report and literature review. Okajimas Folia Anat Jpn. 2012; 88(4): 147-151, doi: 10.2535/ofaj.88.147, indexed in Pubmed: 22645906.

6. Coco D, Cecchini S, Leanza S, et al. Inferior vena cava duplication: incidental case in a young woman. Case Rep Radiol. 2016; 2016: 3071873, doi: 10.1155/2016/3071873, indexed in Pubmed: 27217964.

7. Ghandour A, Partovi S, Karuppasamy K, et al. Congenital anomalies of the IVC-embryological perspective and clinical relevance. Cardiovasc Diagn Ther. 2016; 6(6): 482-492, doi: 10.21037/cdt.2016.11.18, indexed in Pubmed: 28123970.

8. Itoh $\mathrm{M}$, Moriyama $\mathrm{H}$, Tokunaga $\mathrm{Y}$, et al. Embryological consideration of drainage of the left testicular vein into the ipsilateral renal vein: analysis of cases of a double inferior vena cava. Int J Androl. 2001; 24(3): 142-152, doi: 10.1046/j.1365-2605.2001.00286.x, indexed in Pubmed: 11380703.

9. Kandpal H, Sharma R, Gamangatti S, et al. Imaging the inferior vena cava: a road less traveled. Radiographics. 2008; 28(3): 669-689, doi: 10.1148/rg.283075101, indexed in Pubmed: 18480478.

10. Khaledpour $C$, Matanovic P, Rienäcker J, et al. An abdominal aortic aneurysm (AAA) in combination with duplication of the inferior vena cava (IVC), the right renal artery (RRA) and the right renal vein (RRV). Surg Radiol Anat. 1990; 12(1): 73-76, doi: 10.1007/BF02094132, indexed in Pubmed: 2345901.

11. Kudo FA, Nishibe T, Miyazaki K, et al. Left renal vein anomaly associated with abdominal aortic aneurysm surgery: report of a case. Surg Today. 2003; 33(8): 609-611, doi: 10.1007/s00595-003-2536-0, indexed in Pubmed: 12884099.

12. Lamparello BM, Erickson CR, Kulthia A, et al. Congenital anomaly of the inferior vena cava and factor $\mathrm{V}$ Leiden mutation predisposing to deep vein thrombosis. Vasc Health Risk Manag. 2014; 10: 609-613, doi: 10.2147/ VHRM.S66283, indexed in Pubmed: 25395858.
13. Lewis SJ. Observations on a double inferior vena cava: A case report with a literature review. Clin Anat. 1992; 5(3): 227-233, doi: 10.1002/ca.980050307.

14. Machnicki A, Grzybiak M. Variations in testicular arteries in fetuses and adults. Folia Morphol. 1997; 56(4): 277-285, indexed in Pubmed: 9635363.

15. Malaki M, Willis AP, Jones RG. Congenital anomalies of the inferior vena cava. Clin Radiol. 2012; 67(2): 165-171, doi: 10.1016/j.crad.2011.08.006, indexed in Pubmed: 22070941.

16. McNeil JC, Whipp KP, Lambert HW. Unique variant of a double inferior vena cava with interiliac communication: Review of clinical and surgical relevance. Int J Anat Var. 2016; 9: 35-38.

17. Moore K, Persaud T. The Developing Human. Clinically Oriented Embryology. 7th ed. Elsevier Science, USA 2003.

18. Natsis K, Apostolidis S, Noussios G, et al. Duplication of the inferior vena cava: anatomy, embryology and classification proposal. Anat Sci Int. 2010; 85(1): 56-60, doi: 10.1007/ s12565-009-0036-z, indexed in Pubmed: 19330283.

19. Ozdemir B, Aldur MM, Celik HH. Multiple variations in the azygos venous system: a preaortic interazygos vein and the absence of hemiazygos vein. Surg Radiol Anat. 2002; 24(1): 68-70, doi: 10.1007/s00276-002-0008-7, indexed in Pubmed: 12197015.

20. Perumal S, Subramaniam S. Missing inferior vena cava: report of a rare case. Int Surg J. 2019; 6(6): 2201, doi: 10.18203/2349-2902.isj20192393.

21. Petik B. Inferior vena cava anomalies and variations: imaging and rare clinical findings. Insights Imaging. 2015; 6(6): 631-639, doi: 10.1007/s13244-015-0431-z, indexed in Pubmed: 26373648.

22. Pineda D, Moudgill N, Eisenberg J, et al. An interesting anatomic variant of inferior vena cava duplication: case report and review of the literature. Vascular. 2013; 21(3): 163-167, doi: 10.1177/1708538113478731, indexed in Pubmed: 23518845.

23. Seema, Singh M. Multiple variations of the azygos venous system: a case report. Int J Anat Var. 2013; 6: 34-35.

24. Senecail B, Lefevre C, Person $\mathrm{H}$, et al. Radiologic anatomy of duplication of the inferior vena cava: a trap in abdominal imaging. A report of 8 cases. Surg Radiol Anat. 1987; 9(2): 151-157, doi: 10.1007/BF02086600, indexed in Pubmed: 3120333.

25. Takagi T, Nozaka Y, Ohsawa T. Double superior venae cavae with bilateral inferior venae cavae. Kaibogaku Zasshi. 1982; 57(1): 9-14, indexed in Pubmed: 7090729.

26. Tamizifar B, Seilani P, Zadeh MR. Duplication of the inferior vena cava and thrombosis: A rare case. J Res Med Sci. 2013; 18(10): 911-913, indexed in Pubmed: 24497866.

27. Tohno Y, Tohno S, Azuma C, et al. One case of the double inferior venae cavae found in a Japanese man. J Nara Med Assoc. 2006; 57(6): 193-197.

28. Wagner J, Bogusch G. An abnormal pattern of blood vessels in the retroperitoneal space with a duplicated inferior vena cava in an adult: a case report. Surg Radiol Anat. 1993; 15(3): 201-205, doi: 10.1007/BF01627706, indexed in Pubmed: 8235963.

29. Wang LT, Lo HC, Yu DS, et al. Ureteral obstruction caused by a duplicated anomaly of inferior vena cava. Int J Urol. 2005; 12(9): 842-844, doi: 10.1111/j.14422042.2005.01171.x, indexed in Pubmed: 16201983.

30. Williams PL, Bannister H, Berry MM, Collins P, Dyson M, Dussek JE, Fergusson MWJ. eds. Gray's Anatomy. 38th ed. Churchill Livingstone, London 1995.

31. Xue HG, Yang CY, Asakawa M, et al. Duplication of the inferior vena cava associated with other variations. Anat Sci Int. 2007; 82(2): 121-125, doi: 10.1111/j.1447073X.2006.00153.x, indexed in Pubmed: 17585569. 